\title{
Study of bacterial attachment on the rough surfaces
}

\author{
Haritha Senthilraj ${ }^{1}$, Banu Pradheepa Kamarajan ${ }^{1,2}$, Muthusamy Ananthasubramanian ${ }^{1 *}$ \\ \{biosubramanian@gmail.com ${ }^{1}$,haribioteck@gmail.com², banu150888@gmail.com³ \\ Department of Biotechnology, PSG College of Technology, Coimbatore, India ${ }^{1}$, Department of \\ Biomedical Engineering, Sri Ramakrishna Engineering College, Coimbatore, India ${ }^{2}$
}

\begin{abstract}
Bacterial attachment is a menace in medical implants that inevitably demands revision surgery, increasing the patient morbidity and cost involved. Numerous strategies such as use of antibodies, combination of antibiotics, contact killing surfaces, coatings with functional DNase I, glycoside hydrolase, surface derivatization and functionalization are practiced to combat biomaterial associated infections. Generally, coatings with bioactive compounds have limited shelf-life and require cold-chain. This study aims to develop nano-scale architectures on two-dimensional surface and, test their efficiency in reducing bacterial attachment. In this study, surface architectures were generated on the glass coverslip by rasping with different grits of silicon carbide paper, and were characterized using Atomic Force Microscope. Common human pathogens such as Staphylococcus aureus, Pseudomonas aeruginosa and Staphylococcus epidermidis were tested for their attachment on the coverslips. The results indicate that the nano-scale surface architecture developed by rasping the coverslip with p1000 grit reduced bacterial attachment by $50-80 \%$ compared to control (unmodified coverslip). Ironically, surface architecture developed by rasping the coverslip with $\mathrm{p} 80$ grit increased the bacterial attachment under both static and dynamic conditions to about $30-40 \%$ compared to control. The study suggests that knowledge on bacterial attachment on different surface architectures would facilitate fabrication of medical implants with defined surface structures that restricts bacterial colonization..
\end{abstract}

Keywords: Surface roughness, bacteria, attachment, biomaterial.

\section{Introduction}

Bacteria attaches to almost all the surfaces. Bacterial attachment could be beneficial or detrimental depending on the surface of attachment. Bacterial biofilms on the microbial fuel cell or treatment plants are beneficial, whilst the biofilms on the ship hull and bioreactor vessels, medical implants and prosthesis are regarded notorious. Bacterial biofilms on the ship hull significantly increases fuel consumption and, biofilms on bioreactor vessels are difficult to clean and consequently affects the efficiency of the process and purity of the product.

Bacterial colonization on the orthopedic implants causes implant failure and aseptic loosening. Infections in bone implants occur mainly due to Staphylococcus aureus, 20-25\% [1], Staphylococcus epidermidis, 36-45\% [2] and Pseudomonas aeruginosa 8-11\% [3]. Biomaterial associated infection besides causing patient morbidity, requires a revision surgery, increasing the cost involved [4]. Biomaterials with surface modification to prevent bacterial attachment are desired. Conventional modifications involve coating the implant material with antibiotics [5], functional DNase I [8], glycoside hydrolase [9], surface derivatization and functionalization [10], developing contact-killing surfaces [6] or impregnating antibiotics into 
the electrospun [7] implant material for sustained release. Such coatings with bioactive compounds besides having limited shelf-life and cold-chain requirement, might likely fail when bacteria develop resistance. Physical modification of the implant surface is desirable as the bacteria developing resistance against the physical structures is most unlikely.

Controlled rough surfaces could be generated using $\mathrm{SiC}$ grit paper which requires neither technical expertise nor high energy/cost. For initial studies on bacterial attachment to surfaces with different roughnesses, $\mathrm{SiC}$ rasped surfaces would be a good alternative. This study aims to understand the bacterial behavior on the rough surfaces generated by rasping with different grades of grit paper.

\section{Materials And Methods}

\section{A. Bacterial cultures}

Four bacterial cultures namely, Pseudomonas aeruginosa PAO1 (MTCC 3541), Pseudomonas aeruginosa (MTCC 1688), Staphylococcus aureus (MTCC 7443) and Staphylococcus epidermidis (MTCC 3615) were procured from Microbial Type Culture Collection (MTCC), Chandigargh, India. Bacteria were maintained in glycerol stock at $-80^{\circ} \mathrm{C}$ and, cultured on nutrient broth kept at $37^{\circ} \mathrm{C}$ under shaking condition.

\section{B. Surface roughness}

Microscopic glass cover slips (Blue star) were cleaned with millipore water (Resistivity 18.2 M $\Omega . \mathrm{cm}$ ) and air-dried. Surface roughness was generated by rasping the coverslip surface using different grades of silicon carbide paper (p80, p600 and p1000) in one direction. The roughnesses generated were imaged and measured using Atomic Force Microscopy (NTMDT, Russia) by contact mode. Unscratched glass coverslip was kept as control.

\section{Surface hydrophobicity}

The water contact angles of the untreated and rasped coverslips were measured using the goniometer (Digidrop GBX, France) by contour mode. $5 \mu \mathrm{L}$ of water was used.

\section{Bacterial attachment}

The glass coverslips were rasped with p80, p600 and p1000 and, unscratched coverslip (control) was stuck to the bottom of the 6-well plate using double-sided adhesive. Single colonies of the bacteria were inoculated separately in nutrient broth and cultured at $37^{\circ} \mathrm{C}$ at shaking condition for overnight. The cultures were centrifuged for 7,000 rpm for 6 min to pellet down the cells. The cells were resuspended in fresh medium and the OD600 was adjusted to 1.0 using nutrient broth and, added to the glass coverslips stuck in 6-well plate. The plates were incubated at $37^{\circ} \mathrm{C}$ for $5 \mathrm{~min}, 10 \mathrm{~min}, 15 \mathrm{~min}$ and $20 \mathrm{~min}$ to study initial bacterial attachment. Similar experimental setup incubated for $24 \mathrm{~h}, 48 \mathrm{~h}$ and $72 \mathrm{~h}$ at $37^{\circ} \mathrm{C}$ were also studied. The plates were incubated under static and shaking conditions.

After the incubation time, coverlips were rinsed gently in Millipore water, stained with $0.5 \%$ methylene blue and visualized under light microscope $(40 \mathrm{X})$. The images captured were enumerated using Image $\mathrm{J}$ software.

Percentage of bacterial reduction on the scratched coverslips was calculated as

$\%$ Bacterial reduction $=\frac{(\text { number of cells on control })-(\text { number of cells on rasped coverslip })}{\text { number of cells on control }} \times 100$ 


\section{Results And Discussion}

\section{A. Surface Roughness}

The surface roughness generated on the glass coverslips were investigated using Atomic Force Microscope. The images of the scratched coverslips had ridges and grooves with varying roughnesses as represented in figure 1.
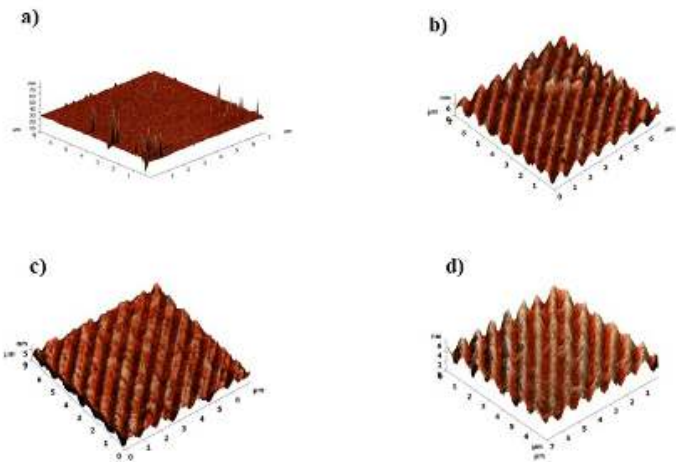

Figure 1. Representative image of glass cover slip control (a), coverslip scratched with silicon carbide paper p80 (b), p600 (c) and p1000 (d). The scanned area is 7x7 sq. $\mu \mathrm{m}$.

The average surface roughness, root mean square, symmetry of distribution, variation in peak values and other measured parameters are provided in table 1 . From the table 1 , it could be observed that control has the lowest average surface roughness of 0.711 , while coverslip scratched with p80 grit had the coarse surface with average surface roughness of 1.439 . Increasing the grit number eventually decreased the peak height and roughness.

Table 1. Roughness parameters of the glass cover slips obtained using Atomic Force Microscopy

\begin{tabular}{|c|c|c|c|c|c|c|}
\hline $\begin{array}{l}\text { ISO grit } \\
\text { designation }\end{array}$ & $\begin{array}{l}\text { Average surface } \\
\text { roughness (Ra) } \\
(\mathrm{nm})\end{array}$ & $\begin{array}{l}\text { Root Mean } \\
\text { Square (Rq) } \\
(\mathbf{n m})\end{array}$ & $\begin{array}{l}\text { Surface } \\
\text { skewness } \\
(\mathrm{nm})\end{array}$ & $\begin{array}{l}\text { Coefficient of } \\
\text { kurtosis (nm) }\end{array}$ & $\begin{array}{l}\text { Peak-to- } \\
\text { peak } \\
\text { distance } \\
(\mathrm{nm})\end{array}$ & $\begin{array}{l}\text { Ten } \\
\text { point } \\
\text { height } \\
\text { (nm) }\end{array}$ \\
\hline Control & 0.582 & 1.669 & 13.228 & 271.567 & 78.58 & 38.48 \\
\hline p80 & 1.439 & 1.792 & 0.428 & -0.039 & 19.096 & 8.853 \\
\hline p600 & 0.879 & 1.056 & -0.349 & -0.559 & 8.101 & 3.935 \\
\hline p1000 & 0.711 & 0.848 & -0.075 & -0.481 & 6.481 & 3.217 \\
\hline
\end{tabular}

Variation in the surface hydrophobicity of the control and rasped coverslips were studied using water contact angle. From the figure 2, it could be observed that unscratched glass 
coverslip (control) is least hydrophobic with the water contact angle of $57.27 \pm 1.4$ and lowest average surface roughness, whilst the coverslip scratched with p1000 grit was highly hydrophobic having the water contact angle of 71.00 \pm 3.21 . Scratching the glass coverslip with increasing grades of grit paper proportionately decreases the roughness. However, no correlation between roughness and its relative hydrophobicity were observed. From the results it could be observed that, except for the coverslip rasped with p1000 grit, all other coverslips including the control had water contact angle from 55-63. Surfaces with water contact angle between 40 and 70 tend to enhance cell adhesion and growth [11]. Though surface hydrophobicity is not the only parameter that affects bacterial adhesion, water contact angle of the coverslip scratched with p1000 grit could also have played a role in restricting bacterial attachment.

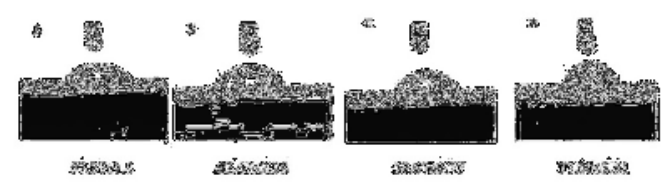

Figure 2. Water contact angle of control (a) glass coverslip scratched with p80 (b), p600 (c) and p1000 (d)

\section{B. Bacterial attachment}

Bacteria attached to the coverslips under both static and dynamic conditions were enumerated after 5,10,15 and $20 \mathrm{~min}$. From figure 3 and 4, it could be observed that bacterial reduction (lower bacterial attachment) is observed on the coverslip scratched with p1000 grit compared to the control, under both static and dynamic conditions. The percentage of reduction in the bacterial attachment on the coverslip scratched with p1000 grit is nearly 2-3 times lesser than the bacteria attached to the coverslip scratched with p600 grit. In addition, lower bacterial reduction (higher bacterial attachment) is observed on the coverslip scratched with p80 grit. Similar study carried out on PMMA reported a significant decrease in bacterial adhesion on nano-scale roughness created by p1200 grit, while micro-scale roughness produced by 400 and p120 had a significant rise in bacterial adhesion [12]. 

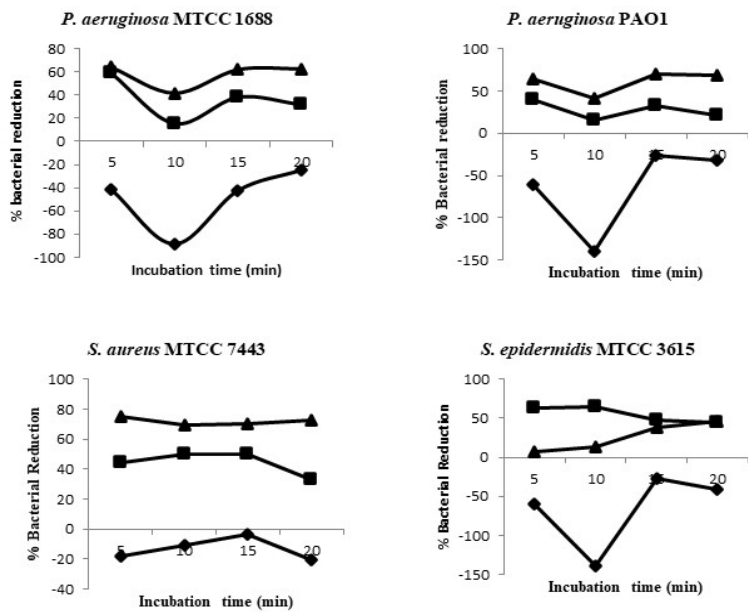

Figure 3. Reduction in bacterial attachment on the scratched coverslips p80 ( $\mathrm{p} 600(\boldsymbol{\Delta})$ and p1000 ( ) with reference to the unscratched coverslip (control) under static condition
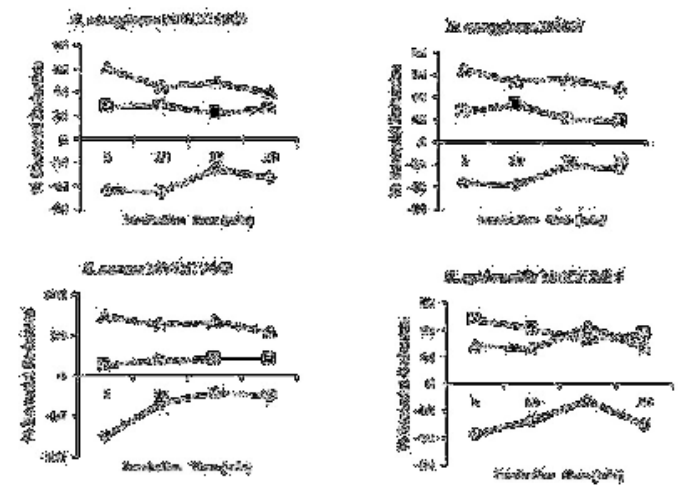

Figure 4. Reduction in bacterial attachment on the scratched coverslips p80 ( $\mathbf{\square})$, p600 ( $\mathbf{\Delta}$ ) and p1000 ( $\diamond$ with reference to the unscratched coverslip (control) under dynamic condition

\section{Bacterial multiplication}

Besides bacterial attachment, bacterial multiplication on the coverslips under both static and dynamic conditions was enumerated after 1, 2 and 3days. From figure 5 and 6 , it could be observed that higher percent of bacterial reduction (lower bacterial multiplication) was observed on the coverslip scratched with p1000 grit compared to the control, under both static and dynamic conditions compared to the rest of the test slips. It could also be observed that, despite minor variations, higher number of bacteria attachment and multiplication were 
observed on the coverslip scratched with p80 grit, suggesting that it encourages bacterial attachment and less likely supports bacterial reduction.

The coverslip scratched with p1000 grit, despite possessing greater hydrophobicity among the test coverslips, has the average peak height of $3.2 \mathrm{~nm}$ that are approximately $6 \mathrm{~nm}$ apart. The dimensions were likely less conducive for the bacteria to adhere. On the contrary, the coverslip scratched with p80 grit has the average peak height of $8.8 \mathrm{~nm}$ that are spaced approximately $19 \mathrm{~nm}$ apart, which favoured bacterial attachment and multiplication. Lorenzetti et al, reported that macro-scale roughness encourages bacterial attachment between the grooves, while the closer peaks in the nano-scale roughness hinders bacteria from developing minimum focal adhesions [13].
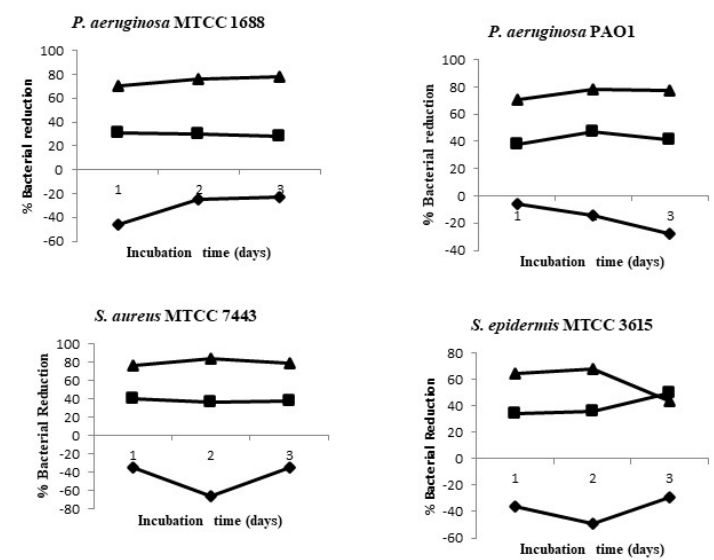

Figure 5. Reduction in bacterial multiplication on the scratched coverslips p80 ( ), p600 ( $\boldsymbol{a})$ and p1000 ( with reference to the unscratched coverslip (control) under static condition.
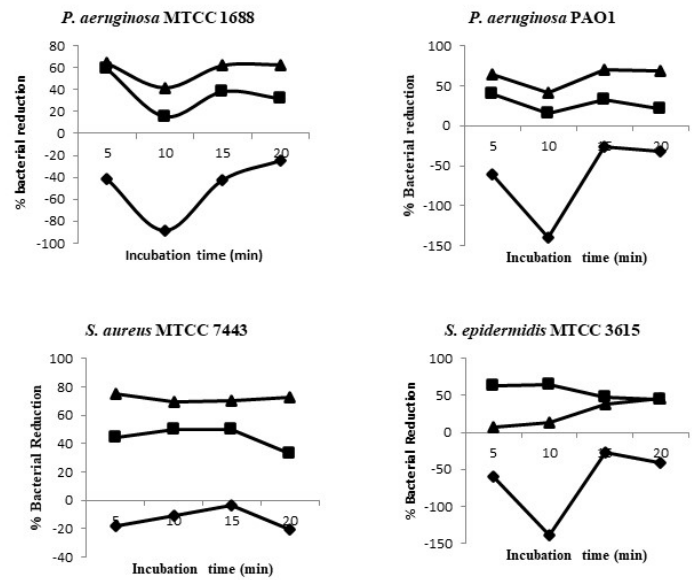
Figure 6. Reduction in bacterial multiplication on the scratched coverslips p80 ( $\triangleleft)$, p600 ( $\boldsymbol{\square})$ and p1000 ( $\Delta$ ) with reference to the unscratched coverslip (control) under dynamic condition.

In the previous study carried out on the sodium fluoride etched glass surface also suggested that nano-rough surface restricted the attachment of common bacteria such as Staphylococcus aureus, Pseudomonas aeruginosa, Escherichia coli and Bacillus subtilis [14].

Generally, bacteria selectively attach to specific surface topography [15]. Nano-rough surface significantly reduced the attachment of both Gram positive, Gram negative cocci/rod shaped bacteria. This could be due to bacterial shape and size [16], texture modification [17], entrapped air between the peaks that repels bacteria/readily detaches attached bacteria during washing [11] or the relation between roughness dimensions and size of bacteria [18]. Interestingly, Yuan et al. reports that those bacteria that succeeded in the initial attachment to specific surface roughness were detached during washing [11]. Ironically, Perera-Costa et al reported that defined micro-scale surface architecture developed on polydimethylsiloxane restricted bacterial attachment by $30-45 \%$ compared to the smooth control surface [16]. Surface roughness developed using sand paper abrasion is desirable and are less susceptible to bacterial attachment [17].

\section{Conclusion}

In conclusion, employing surface roughness to restrict bacterial attachment avoiding antimicrobials seems promising to combat bacterial colonization and subsequent biofilm formation. Since the proposed strategy utilizes physical components majorly rather than depending on the surface chemistry, chances of bacteria developing resistance against fietailored surface roughness is most unlikely. This art of generating desired surface patterns and roughness when bespoke could be used to in wide range of applications such as bioreactor vessels, orthopaedic implants, ship hulls and as self-cleaning means on frequently touched surfaces.

\section{Acknowledgements}

The authors thank Department of Biotechnology, PSG College of Technology for providing the facilities to carry out the work.

\section{References}

[1] Barth E, Myrvik QM, Wagner W, Gristina AG, In vitro and In vivo Comparative Colonization of Staphylococcus aureus and Staphylococcus epidermidis on Orthopaedic Implant Materials. Biomater. 10:325-328 (1989).

[2] Mack D, Path FRC, Davies AP, Harris LG, Jeeves R, Pascoe B, Wilkinson TS, Staphylococcus epidermidis in Biomaterial-Associated Infections. In: Moriarty TF, Zaat SAJ, Busscher HJ (ed) Biomaterials Associated Infection: Immunological Aspects and Antimicrobial Strategies. Springer, New York, DOI 10.1007/978-1-4614-1031-7 (2013). 
[3] Delden VC, Iglewski BH, Cell to Cell Signalling and Pseudomonas aeruginosa Infections. Emerg. Infect. Dis. 4:551-560 (1998).

[4] Busscher HJ, van der Mei HC, Subbiahdoss G, Jutte PC, van den Dungen J, Zaat SAJ, Schultz MJ, Grainger DW, Biomaterial-Associated Infection: Locating the Finish Line in the Race for the Surface. Sci Trans Med. 4:153 (2012).

[5] Romanò CL, Scarponi S, Gallazzi E, Romanò D, Drago L, Antibacterial coating of implants in orthopaedics and trauma: A classification proposal in an evolving panorama. J. Orthop. Surg. Res. 10(1):1-11 (2015).

[6] Tiller JC, Liao C-J, Lewis K, Klibanov AM, Designing surfaces that kill bacteria on contact. PNAS 98(11):5981-5985 (2001).

[7] Prabu P, Kim KW, Antimicrobial Drug Release Scaffolds of Natural and Synthetic Biodegradable Polymers. Macromol. Res. 16(4):303-307 (2008).

[8] Swartjes JJTM, Das T, Sharifi S, Subbiahdoss G, Sharma PK, Krom BP, Busscher HJ, van der Mei $\mathrm{HC}$, A functional DNase I coating to prevent adhesion of bacteria and the formation of biofilm. Adv. Funct. Mater. 23(22):2843-2849 (2013).

[9] Asker D, Awad TS, Baker P, Howell PL, Hatton BD (2018). Non-eluting, surface-bound enzymes disrupt surface attachment of bacteria by continuous biofilm polysaccharide degradation. Biomater. 167: 168-176 (2018).

[10] Widmer A. F. (2001) New Developments in Diagnosis and Treatment of Infection in Orthopedic Implants. Clin. Infect. Dis. 33 (Suppl 2): S 94-106 (2001).

[11] Yuan Y, Hays MP, Hardwidge PR, Kim J, Surface characteristic influencing bacterial adhesion to polymeric substrates. Rsc Adv. 7:14254-14261 (2017).

[12] Katsikogianni M, Missirlis YF, Concise review of mechanisms of bacterial adhesion to biomaterials and of techniques used in estimating bacteria-material interaction. Eur. Cells Mater. 8:37-57 (2004).

[13] Lorenzetti M, Dogsa I, Stosicki T, Stopar D, Kalin M, Kobe S, Novak S, The Influence of surface modification on Bacterial Adhesion to Titanium-based substrates. ACS Appl. Mater. Interfaces 7(3):1644-1651 (2015).

[14] Kamarajan BP, Thankappan S, and Ananthasubramanian M, Relevance of Surface Asperities in Scheming Cellular Attachment to Minimize Biomaterial Associated Infections. Trends Biomater. Artif. Organs, 29(2): 140-145 (2015).

[15] M. Tholkapiyan, A.Mohan, Vijayan.D.S , "A survey of recent studieson chlorophyll variation in Indian coastal waters", IOP Conf. Series: Materials Science and Engineering 993 (2020) 012041, doi:10.1088/1757-899X/993/1/012041.

[16] Perera-costa D, Bruque JM, Gonzalez-Martin ML, Gomez-Garcia AC, Vadillo-Rodriguez V, Studying the influence of Surface Topography on Bacterial Adhesion using Spatially Organized Microtopographic Surface Patterns. Langmuir 30(16): 4633-4641 (2014).

[17] Duarte PM, Reis AF, de Freitas PM, Ota-Tsuzuki C, Bacterial adhesion on smooth and rough titanium surfaces after treatment with different instruments. J. Peridontol. 80(11): 1824-1832 (2009).

[18] Diaz C, Cortizo MC, Schilardi PL, Saravia SGG, Mele MAFL, Influence of the Nano-micro structure of the surface on bacterial adhesion. Mat. Res. 10(1), (2007). 